\title{
Developing a whole-school mental health and wellbeing intervention through pragmatic formative process evaluation: a case-study of innovative local practice within The School Health Research network
}

\author{
Nina Gobat ${ }^{1 *}\left(\mathbb{D}\right.$, Hannah Littlecott ${ }^{2}$, Andy Williams $^{3}$, Kirsten McEwan ${ }^{4}$, Helen Stanton ${ }^{5}$, Michael Robling ${ }^{5}$,
} Stephen Rollnick ${ }^{3}$, Simon Murphy ${ }^{2}$ and Rhiannon Evans ${ }^{2}$

\begin{abstract}
Background: The evidence-base for whole school approaches aimed at improving student mental health and wellbeing remains limited. This may be due to a focus on developing and evaluating de-novo, research-led interventions, while neglecting the potential of local, contextually-relevant innovation that has demonstrated acceptability and feasibility. This study reports a novel approach to modelling and refining the programme theory of a whole-school restorative approach, alongside plans to scale up through a national educational infrastructure in order to support robust scientific evaluation.

Methods: A pragmatic formative process evaluation was conducted of a routinized whole-school restorative approach aimed at improving student mental health and wellbeing in Wales.

Results: The study reports the six phases of the pragmatic formative process evaluation. These are: 1) identification of innovative local practice; 2) scoping review of evidence-base to identify potential programme theory; outcomes; and contextual characteristics that influence implementation; 3) establishment of a Transdisciplinary Action Research (TDAR) group; 4) co-production and confirmation of an initial programme theory with stakeholders; 5) planning to optimise intervention delivery in local contexts; and 6) planning for feasibility and outcome evaluation. The phases of this model may be iterative and not necessarily sequential.

Conclusions: Formative, pragmatic process evaluations can support researchers, policy-makers and practitioners in developing robust scientific evidence-bases for acceptable and feasible local innovations that do not already have a clear evidence base. The case of a whole-school restorative approach provides a case example of how such an evaluation may be undertaken.
\end{abstract}

Keywords: Process evaluation, Intervention development, Restorative approach, Schools-based intervention, Mental health, Methodology

\footnotetext{
* Correspondence: nina.gobat@phc.ox.ac.uk

${ }^{1}$ Nuffield Department of Primary Care Health Sciences, University of Oxford, Radcliffe Observatory Quarter, Woodstock Road, Oxford OX2 6GG, UK

Full list of author information is available at the end of the article
}

(c) The Author(s). 2021 Open Access This article is licensed under a Creative Commons Attribution 4.0 International License, which permits use, sharing, adaptation, distribution and reproduction in any medium or format, as long as you give appropriate credit to the original author(s) and the source, provide a link to the Creative Commons licence, and indicate if changes were made. The images or other third party material in this article are included in the article's Creative Commons licence, unless indicated otherwise in a credit line to the material. If material is not included in the article's Creative Commons licence and your intended use is not permitted by statutory regulation or exceeds the permitted use, you will need to obtain permission directly from the copyright holder. To view a copy of this licence, visit http://creativecommons.org/licenses/by/4.0/. The Creative Commons Public Domain Dedication waiver (http://creativecommons.org/publicdomain/zero/1.0/) applies to the data made available in this article, unless otherwise stated in a credit line to the data. 


\section{Background}

In recent years there has been a rapid expansion in the number of frameworks available to support the development, modelling and prototyping of complex population health interventions [1, 2]. Despite offering important theoretical, methodological and pragmatic guidance, these frameworks have been largely applied to the development of de novo, research-led interventions rather than to the approaches already in routine practice.

There are distinct benefits of evaluating locally embedded interventions,. First, intervention development frameworks privilege co-production, particularly in regard to developing intervention models that couple stakeholders' understanding of the problem with scientific evidence. Evaluation of embedded local innovation offers insight into stakeholders' theorisation of the problem, as they are likely developed in response to these contextually informed understandings. Second, in accordance with realist [3-5] and complex systems perspectives [6, 7], intervention outcomes should be understood as being the result of interactions between the intervention's causal mechanisms and the context into which they are introduced. In the case of routine practice, much of the dynamic interplay between these mechanisms and context are already emergent. This makes it possible move beyond hypothetical assumptions about how an intervention might operate when introduced to a specific context or how the system will (re) orientate itself following this disruption. Third, acceptability will likely already have transpired, and variations in engagement across different stakeholders may be apparent.

Pragmatic formative process evaluation is an approach that can help the retrospective modelling of locally embedded innovations [8]. It is informed by frameworks used to develop de novo interventions, which tend to include the following research phases: conduct a review to map the nature of the problem and potential intervention responses; establish a stakeholder groups to govern the intervention development process; co-produce intervention materials; test and adapt the intervention in context; and progress to feasibility and/or outcome evaluation [1, 2]. For pragmatic formative evaluations, additional stages will likely need to be considered. These centre on identifying local innovative practice and engaging stakeholders in modelling a programme theory that may have been developed by local practitioners. Transdisciplinary action research (TDAR) approaches have been identified as a way of cultivating and sustaining collaborations to support such additional activities, and may be useful to the pragmatic evaluation approach [9].

Despite their potential value, there is a paucity of empirical examples on how to undertake pragmatic formative process evaluations of complex population health interventions. The present study aims to address this gap by a presenting a worked example. It describes the phases of evaluation undertaken, reflects upon the limitations of the process, recognises the challenges encountered and provides recommendations for the future improvement of the research design. The study draws upon a secondary-school based restorative practice intervention as a case example for testing and developing this approach.

Intervention: The intervention is a system-level approach to restorative practice that has been delivered in a secondary school in Wales since 2008. Restorative practices include relationship-focused actions, which can be implemented at the targeted, universal or whole school level, to impact upon a range of outcomes, including mental health and wellbeing $[10,11]$. They often include activities spanning the range of socio-ecological domains (i.e. intrapersonal; interpersonal; organisational; community). A central tenet is to encourage individuals to take responsibility for their actions, with positive engagement in conflict resolution and relationship repair being key to the approach [12]. Key contextual influences that impact on programme theory and implementation practices have not been extensively explored in the existing evidence base. Neither has unintended or potentially harmful causal pathways.

\section{Methods}

A six phased framework was applied to model the intervention and plan potential for further optimisation of delivery and outcome evaluation. These were 1) identification of innovative local practice; 2) scoping review to identify programme theory; contextual characteristics; implementation and outcomes; 3) establishment of a TDAR group; 4) co-production and confirmation of a programme with stakeholders; 5) planning to optimise intervention delivery in local contexts; and 6) planning for feasibility and outcome evaluation. These stages are presented in in detail in the results, with the methodology focusing on the study sample and research methods used.

\section{Case study}

The study comprised case study methodology with one mixed gender secondary school in Wales. The school serves students aged 11-18 years and had more than 1500 registered students in 2016. It has below average student Free School Meal eligibility (FSM) (2016 threeyear Welsh average $17.3 \%$ ), which is routinely used as a proxy measure for socio-economic deprivation. It has an above average proportion of students achieving 5 General Certificate of Secondary Education (GCSEs) at Grade $\mathrm{A} *-\mathrm{C}$ including English/Welsh and Mathematics (2016 Welsh average 57.9\%) [13]. GCSEs are statutory 
tests taken in Year 11 (age 15-16 years) in England and Wales. The school was identified via the national School Health Research Network (SHRN) infrastructure [14].

\section{Participant sample and recruitment}

Staff and students participated in data generated at Phase 4. The demographic characteristics of participants are presented in Table 1 . Students were purposively sampled for maximum variation in gender and age. A total number of 22 students participated. Staff members were similarly sampled to ensure maximum variation, with. Eighteen staff taking part. Staff and students were recruited through the study gatekeeper who was a member of the TDAR group. This individual was a member of staff in the Senior Leadership Team with responsibility for pastoral support, including the school's implementation of the restorative practice approach. The gatekeeper was asked to purposively recruit participants to ensure diversity.

\section{Data collection}

Focus groups were selected as the most appropriate method for working with participants, anticipating that interactions would elicit inconsistencies in understandings of the intervention and context. Two focus groups were held with students and two with staff. Researchers used a semi-structured topic guide to steer the discussions (see supplementary files). Focus groups lasted an average of one hour $12 \mathrm{~min}$. Two researchers moderated them. The first set of focus groups were intended to coproduce the programme theory and logic model, while the second set intended to confirm them. An initial, candidate logic model was developed by the TDAR group from the extant research evidence. It was used to start

Table 1 Demographic Characteristics of Case Study Participants at Phase 4

\begin{tabular}{|c|c|c|c|c|c|c|}
\hline & \multicolumn{2}{|c|}{$\begin{array}{l}\text { Programme Theory/Logic Model } \\
\text { Co-production }\end{array}$} & \multicolumn{2}{|c|}{$\begin{array}{l}\text { Programme Theory/Logic Model } \\
\text { Confirmation }\end{array}$} & \multicolumn{2}{|c|}{$\begin{array}{l}\text { Participants who took part in both co- } \\
\text { production and confirmation }\end{array}$} \\
\hline & Group 1 & Group 2 & Group 1 & Group 2 & Group 1 & Group 2 \\
\hline \multicolumn{7}{|l|}{ Students } \\
\hline Total students & 8 & 7 & 8 & 7 & 1 & 7 \\
\hline \multicolumn{7}{|l|}{ Gender } \\
\hline Male & 5 & 4 & 5 & 4 & - & 4 \\
\hline Female & 3 & 3 & 3 & 3 & 1 & 3 \\
\hline \multicolumn{7}{|l|}{ Year group } \\
\hline Year 7 & 1 & 2 & 2 & - & - & - \\
\hline Year 8 & 1 & 3 & 3 & 2 & - & 2 \\
\hline Year 9 & & - & - & 3 & - & 3 \\
\hline Year 10 & 1 & 2 & 2 & 2 & 1 & 2 \\
\hline Year 11 & 2 & - & - & - & - & - \\
\hline Year 12 & 2 & - & 1 & - & - & - \\
\hline Year 13 & 1 & - & $N / A^{a}$ & N/A & $N / A$ & $N / A$ \\
\hline \multicolumn{7}{|l|}{ Staff } \\
\hline Total staff & 6 & 7 & 8 & 5 & 5 & 4 \\
\hline \multicolumn{7}{|l|}{ Gender } \\
\hline Male & 1 & 1 & - & - & - & - \\
\hline Female & 5 & 6 & 8 & 5 & 5 & 4 \\
\hline \multicolumn{7}{|l|}{ Role } \\
\hline Support staff ${ }^{b}$ & 3 & 1 & 3 & 1 & 2 & - \\
\hline Teaching staff & 1 & 1 & 1 & 2 & 1 & - \\
\hline Form tutor & 1 & 1 & - & - & 2 & 2 \\
\hline Leadership role $^{c}$ & 1 & 3 & 2 & 2 & - & - \\
\hline School governor & - & 1 & - & - & - & - \\
\hline Admin staff & - & - & 1 & - & - & - \\
\hline
\end{tabular}

${ }^{\text {a }}$ Year 13 no longer at school in July 2016

bupport staff members work in the school pastoral support centre

'Leadership staff members include heads of year and heads of faculty 
discussion and was built upon throughout the focus groups. The topic guide considered: perceived programme theory; contextual characteristics; experiences of implementation; outcomes; and recommendations for future enhancements. The logic model was refined after the first focus groups and presented at the second set to elicit areas of consensus, areas of nonconsensus, and continued uncertainties. Data were generated between April 2016 and July 2016.

\section{Ethical procedures}

The Cardiff University School of Medicine Research Ethics Committee approved the study. All participants were provided with information sheets prior to study commencement, along with the opportunity to ask any questions. Written informed consent was obtained from all participants, with opt-out guardian consent being secured for students.

\section{Data analysis}

Data were audio recorded, transcribed verbatim and reviewed for accuracy. Data collection and analysis were conducted concurrently, with the data from the first set of focus groups being used to inform the questions asked during the second set. Thematic analysis was conducted [15]. Data were initially coded according to the main domains of a logic model (e.g. programme theory; context; implementation; and outcomes). De novo codes were also developed. Coding was undertaken by one researcher and verified by a second. Codes were compared and contrasted to develop themes. The two sets of focus group data were initially considered independently of each other. Themes were then compared across the data to understand changes that emerged through the process of co-producing the programme theory and then confirming it. The final set of themes were confirmed by the wider research team. NVivo10 software was used to support analyses [16].

\section{Results}

The present results describe the six phases of the framework used to identify and model the case of local innovation, in addition to planning to optimise delivery and conduct future feasibility and outcome testing (Fig. 1). These phases are not necessarily sequential and may require repeating a number of times.

\section{Identification of innovative local practice}

The first phase is to identify innovative local practice that warrants progression to modelling and possible outcome evaluation. The researchers identified the case study intervention through the Centre for Development, Evaluation, Complexity and Implementation in Public Health Improvement (DECIPHer) hosted SHRN infrastructure [14]. The network comprised 165 of all secondary schools in Wales $(N=210)$ at the time of study, with representation from all 22 local authority areas. SHRN seeks to optimise research collaboration between researchers, policy-makers and practitioners. One of the central mechanisms to encourage collaborative working is through a programme of knowledge exchange activities, including webinars and stakeholder meetings. At regional meetings, researchers present study data whilst practitioners share examples of innovative practice to improve staff and student health and wellbeing. The innovative practice was presented at a stakeholder event, with the school gatekeeper following up the potential for research collaboration with the SHRN Manager. The Manager identified a relevant academic contact with the requisite expertise to assess the fit of the intervention with the centre's research priorities, formulate

1. Identification of innovative local practice

2. Scoping review to identify need; programme theory; contextual characteristics; implementation; and outcomes

\section{Establishment of a TransDisciplinary Action Research (TDAR) group}

4. Co-production and confirmation of programme theory with stakeholders

5. Planning to optimise intervention delivery in local contexts

\section{Planning for feasibility and outcome evaluation}

Fig. 1 Procedure for conducting the pragmatic formative process evaluation for intervention development and evaluation 
preliminary research questions, consider an appropriate research design, and draw together a research team.

Given the characteristics of the local innovation and its history of implementation in the school, a pragmatic formative progress evaluation was decided upon. Criteria for informing this decision was: 1) Feasibility of programme theory modelling: The researchers questioned if an "intervention" (regardless of type) was in use and that a programme theory, contextual characteristics, implementation and outcomes could be characterised. The school had been recognised as delivering sectorleading, best practice in restorative practice and had been awarded a Restorative Service Quality Mark (RSQM) in 2010. As a consequence of this external validation the researchers felt that there was clear delivery of a restorative practice intervention. 2) Feasibility of implementation and scale-up: The researchers established that the restorative practice had been routinely used and resourced for a substantial period of time (i.e. eight years). The researchers further considered the future traction of the intervention and if it could be scaled-up for evaluation beyond the single case study school, or was so contextually contingent no replication was feasible. There was no indication that the school was atypical so the intervention could not be transported to other secondary schools, and the school had been increasingly invited to share their practices with other schools at a national level due to being recognised as sector leading; 3) Research Co-production: The researchers consulted with the school to ensure they were prepared to participate in a research study and would potentially be committed to future research.

Scoping review to identify programme theory; outcomes; contextual characteristics that influence programme theory and implementation

The second phase is to engage in a scoping or systematic review of the existing scientific research to develop a preliminary understanding of the intervention. This can inform the development of a programme theory, which can serve as the basis to model the real-world case example. A review further supports consideration of the effects of such interventions, and potential unintended causal pathways that might be explored in the primary research [12].

\section{Causal mechanisms and outcomes}

Across the studies there was a lack of specificity around the underpinning programme theory. Rather there were broad principles of how restorative approaches may work, largely through the building, maintaining and restoring of relationships, where individuals take responsibility for their actions and positively engage in relationship repair and conflict resolution $[10,11]$. This may be further supported by changes in classroom management practices and school ethos. The INCLUSIVE intervention provides one of the most theoretically informed approaches [12, 17], hypothesising that through restorative practices, students are more likely to engage with schools' pedagogic practices and embrace rules and ethos. As a result, school connectedness increases and relationships improve. A range of activities at the targeted, universal and whole-school level can be considered as restorative. The approach may be most effective when it is fully adopted at the system level $[18,19]$.

Evaluations of school based restorative approaches have identified a range of measurable intervention outcomes $[12,18,20,21]$. At the student level these include improving mental health and wellbeing [12], social and emotional competencies including empathetic attitudes and self-esteem [22], improved academic attainment [21], reduced bullying [22] and fewer school exclusions $[20,21]$. There has been limited consideration of staff level outcomes and unintended causal pathways remain largely underdeveloped.

\section{Contextual characteristics that influence implementation and programme theory}

The researchers mapped key contextual characteristics that might influence the activation of the programme theory and impact planned implementation. The Context and Implementation of Complex Intervention Framework (CICI) [23] was used as a framework for mapping context and implementation. Table 2 shows how the domains of the Framework were populated from the evidence-base. Although existing research findings did not map onto all of the CICI domains, a number of influences emerged across papers. Epidemiological: Implementation is strengthened by an increase in the prevalence of bullying within the specified context, leading to more support for such approaches [21, 22]. Political: There is increased support for restorative approaches where there is alignment with political/policy priorities, which has often led to direct government funding [12, 18, 20, 24]. Ethical: Restorative approaches are congruent with a belief in a fair and just society where citizens are respected. In such cirumstances they are viewed as a more ethical approach to punitative or criminalised responses [20].

\section{Establishment of a TDAR group}

The third phase is to establish a TDAR Group, which is intended to support the effective collaboration between diverse stakeholders [25]. The model of TDAR strives for equal, mutually beneficial and reciprocal relationships that value public, practitioner and policy-makers knowledge and experience to the same degree as academic knowledge [26]. Therefore, while dominant 


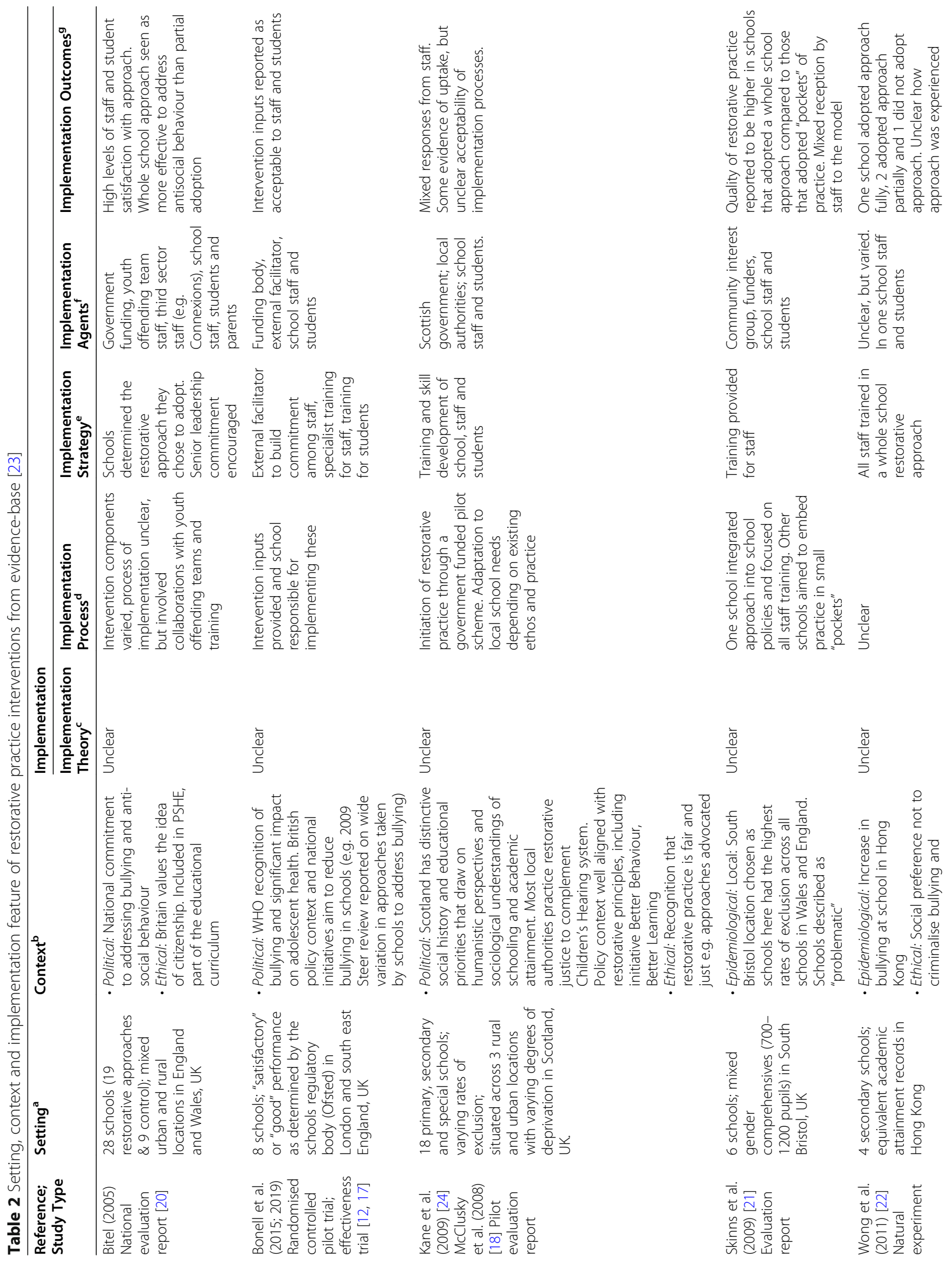




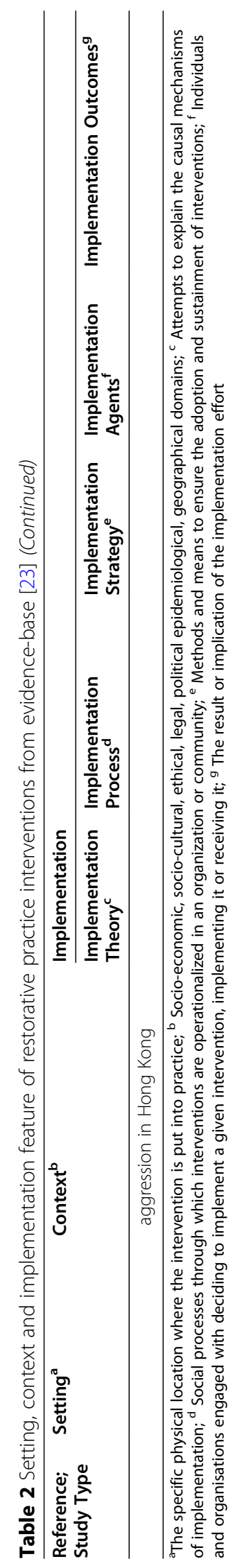


Table $\mathbf{3}$ Logic model for Restorative Practice Intervention

\begin{tabular}{|c|c|c|c|c|}
\hline Inputs & Whole school restorative activities & Causal Mechanisms & Intermediate Outcomes & Outcomes \\
\hline $\begin{array}{l}\text { Initiation } \\
\text { funding } \\
\text { Staff training } \\
\text { in restorative } \\
\text { approach } \\
\text { Policy and } \\
\text { systems } \\
\text { alignment } \\
\text { Benchmarking }\end{array}$ & $\begin{array}{l}\text { Individual-level } \\
\text { - Student-staff: Restorative conversations; } \\
\text { Student needs-led approach to learning } \\
\text { - Student -student: Peer mentoring } \\
\text { - Staff-staff: Peer mentoring } \\
\text { Group level } \\
\text { - Classroom: Circle time; Rotational seating } \\
\text { plans } \\
\text { - Staff: Circle time structure for meetings } \\
\text { and policy development } \\
\text { Organisational level } \\
\text { - Distributive leadership } \\
\text { - Language of school reflects restorative } \\
\text { principles } \\
\text { - Student involvement in high stakes } \\
\text { school level decisions, e.g. school } \\
\text { development planning. } \\
\text { Community level } \\
\text { - Engagement with families } \\
\text { - Engagement with local community }\end{array}$ & $\begin{array}{l}\text { Intra-personal skill development } \\
\text { - empathy, accountability } \\
\text { Enhanced confidence, self- } \\
\text { efficacy and sense of achieve- } \\
\text { ment in learning among } \\
\text { students } \\
\text { Enhanced confidence, self- } \\
\text { efficacy and reduced stress } \\
\text { among staff } \\
\text { Trustworthy, supportive, } \\
\text { respectful relationships } \\
\text { between: } \\
\text { - Student-staff } \\
\text { - Student-student } \\
\text { - Staff-staff } \\
\text { Improved relationships } \\
\text { between school and families } \\
\text { Improved relationships } \\
\text { between school and } \\
\text { community }\end{array}$ & $\begin{array}{l}\text { School connectedness for } \\
\text { students and staff } \\
\text { Student engagement in } \\
\text { learning and pride in } \\
\text { success } \\
\text { Positive school culture (e.g. } \\
\text { supportive, welcoming, } \\
\text { trustworthy, safe and secure) } \\
\text { Enhanced school reputation } \\
\text { in community and student/ } \\
\text { staff pride in school }\end{array}$ & $\begin{array}{l}\text { Primary outcome: } \\
\text { improved student } \\
\text { mental health and } \\
\text { wellbeing } \\
\text { Improved staff mental } \\
\text { health and wellbeing. } \\
\text { Increase in student } \\
\text { attendance } \\
\text { Reductions in student } \\
\text { suspension \& } \\
\text { permanent exclusion. } \\
\text { Reduction in staff } \\
\text { absence } \\
\text { Reduction in students' } \\
\text { referrals to youth } \\
\text { justice } \\
\text { Reduction in bullying } \\
\text { and inappropriate } \\
\text { behaviour } \\
\text { Improved academic } \\
\text { attainment } \\
\text { School } \\
\text { oversubscription }\end{array}$ \\
\hline
\end{tabular}

Contextual characteristics that influence implementation and programme theory

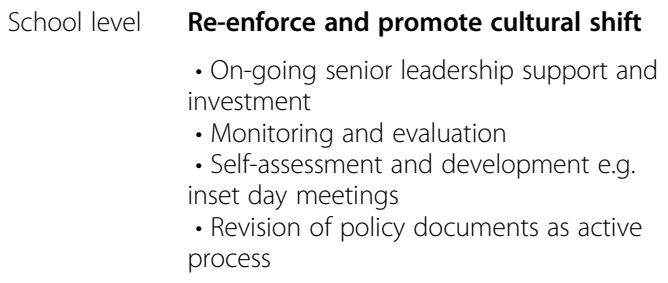

Policy and Contextual drivers that value restorative political level approach (e.g. the Donaldson review recommending curriculum reform in Wales)

\section{Undermine or threaten cultural shift}

- Staff changes and challenge with continuity

- Sub-culture of staff resistance and challenge with consistency

Contextual factors that threaten the approach (e.g. school accountability measures that focus on student results at the exclusion of other metrics) terminology uses the term transdisciplinary, it may be more useful to think in terms of creating transprofessional models of practice. $t$ is underpinned by the principles of action research, and its tenets has been increasingly deployed in guidance around intervention development to ensure that approaches are maximally responsive to the contexts where they are to be implemented [1]. Within a pragmatic formative process evaluation, TDAR can help to bring a comprehensive and nuanced understanding of the intervention that is being modelled, in addition to a rich awareness of the context in which it has been originally delivered.

A TDAR group was set up including researchers from different disciplines (i.e. sociology, public health, psychology and epidemiology) and members of the school community who were on the Senior Management Team. The group comprised eight members. It should be noted that students were not represented, meaning that their perspective was only accommodated during the research. Future studies should better represent the target population in the TDAR group. The group met routinely throughout the duration of the study. Its function was to oversee study conduct, ensure that the study design and processes were being shaped by practice perspectives, support the development of a candidate programme theory and to build relationships to support knowledge translation. It further aided the decision-making about future evaluation (Phase 6), where stakeholders could share views on the value of information from an outcome evaluation and the different types of evidence that would support practice moving forward.

\section{Co-production and confirmation of Programme theory with stakeholders}

The fourth phase is the co-production and confirmation of the programme theory, and associated logic model, with key stakeholders to identify the underpinning causal mechanisms, contextual characteristics, implementation practices and outcomes. Participants developed the programme theory through the first round of focus groups. An initial logic model constructed by the TDAR group from the scoping review findings served as 
a tool to guide this work. The Wisconsin template was used [27]. The output of the logic model is presented in Table 3. A more detailed consideration of context and implementation, as mapped across the CICI framework, is presented in Table 4.

\section{Causal mechanisms}

Both staff and students stated confidence and selfefficacy as being important to the programme theory. Students spoke about feeling equipped to take ownership of their learning, ask for help, and take risks with complex topics, which was largely a consequence of involvement in classroom and school-level decision making. Meanwhile staff suggested that improvements in confidence in the classroom, combined with having the opportunity and skills to express their thoughts and feelings following student conflict, had reduced stress:

STAFF FG1;3: So ... it certainly has made a difference in terms of my wellbeing, giving me more confidence within the classroom ... it's not just looking after student wellbeing, but also staff wellbeing.

The central mechanism for both of these groups of stakeholders was a change in relationships. Students mentioned peer relationships frequently, while staff emphasised relationships between staff and students: In the later instance, one member of staff suggested that circle time redresses power imbalances, creating more supportive interactions:

STAFF FG2; 14- ... the starting with them ... with them was to sort of have a circle time in and listen to them. Find out what they need from me and let them know what I need from them. Erm, and just ... just not being afraid really to sort of break down any barriers between sort of thoughts and feelings ...

Through a shift towards trustworthy and responsive relationships, the school was considered to offer a more positive and supportive culture. These changes led to students experiencing increased school connectedness. This process was further enhanced through a distributed leadership model, involving students in key decision making, such as the design of a new building or appointment of a staff member, with one commenting 'we've had a huge impact with everything in school.'

Additionally, students felt that restorative practices had improved the school's reputation in the community, and relative to other local schools. This had enhanced school connectedness and thus motivation to engage in positive behaviours and improve academic attainment:
STUDENT FG1;5: Because when I first came to the school, ... we were known as "down the hill" and now it's "the comp". Like things have changed. ...

Beyond intended causal pathways, participants considered unintended pathways, which have largely been overlooked in the previous modelling of restorative approaches. This identification illustrates the particular strength of co-production and learning from interventions already in routine practice. For example, participants indicated that the school's improved reputation following adoption of the intervention had led to oversubscription, which had limited access in the community and placed a resource burden on the school.

\section{Outcomes}

Participants identified three key sets of outcomes, which are largely congruent with existing restorative approaches. For both students and staff the reported primary outcome was improved student mental health and wellbeing:

STUDENT FG1; 2- I think wellbeing in the school is kind've increased massively ..,I've got a brother who is 5 years older than me but he came to this school as well and he's told me stories about how there used to be fights every week and people would set off fire extinguishers... then you look at our school now and honestly I'd be surprised if I heard about a fight because it just doesn't happen anymore...(laughs) yeah it's not common any more. I think generally school life has transformed and everything is more positive now. I rarely hear people talk badly about teachers um, everything here seems to be more positive and I think that contributes to all the points these guys have brought up about feeling secure and happy in the environment.

Additional outcomes are presented in Table 3.

\section{Contextual characteristics}

Drawing on the factors identified in the scoping review, the co-production process explored key contextual features that could support the implementation of the intervention and ensure the programme theory worked as intended. These factors were often explained in relation to the reason why restorative practices were initiated.

\section{Epidemiological}

Data indicated that the school had reached a tipping point, and was ready to change. This was largely was due to perceptions of increasingly poor levels of mental health and wellbeing among students, in addition to high 
Table 4 Setting, Context and Implementation Features of Restorative Practice Intervention [23]

\begin{tabular}{|c|c|c|c|c|c|c|}
\hline \multirow[t]{2}{*}{ Setting $^{a}$} & \multirow[t]{2}{*}{ Context $^{b}$} & \multicolumn{5}{|l|}{ Implementation } \\
\hline & & $\begin{array}{l}\text { Implementation } \\
\text { Theoryc }^{c}\end{array}$ & $\begin{array}{l}\text { Implementation } \\
\text { Process }^{\text {d }}\end{array}$ & $\begin{array}{l}\text { Implementation } \\
\text { Strategy }\end{array}$ & $\begin{array}{l}\text { Implementation } \\
\text { Agents }^{f}\end{array}$ & $\begin{array}{l}\text { Implementation } \\
\text { Outcomes }^{9}\end{array}$ \\
\hline $\begin{array}{l}\text { Mixed } \\
\text { comprehensive, } \\
\text { secondary school } \\
\text { (1700 students) in } \\
\text { Wales. Approx. one } \\
\text { quarter of students } \\
\text { live in England. } \\
\text { Lower than the } \\
\text { national average in } \\
\text { terms of social } \\
\text { deprivation } \\
\text { Interactions } \\
\text { Perception among } \\
\text { external } \\
\text { stakeholders that } \\
\text { restorative practice } \\
\text { can work in the } \\
\text { school because } \\
\text { relatively low social } \\
\text { deprivation, with } \\
\text { less antisocial } \\
\text { behaviour. Also } \\
\text { assumption of } \\
\text { greater cohesion in } \\
\text { family and } \\
\text { community groups }\end{array}$ & 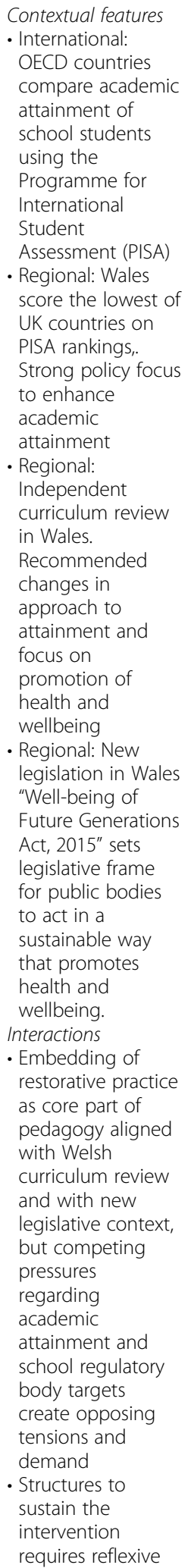 & $\begin{array}{l}\text { Diffusion of } \\
\text { innovation, where } \\
\text { restorative practice } \\
\text { initially adoptedby } \\
\text { the senior } \\
\text { leadership. } \\
\text { Recognition that } \\
\text { staff and student } \\
\text { groups would } \\
\text { adopt the } \\
\text { intervention at } \\
\text { different times and } \\
\text { in different ways } \\
\text { (e.g. "early" vs. "late" } \\
\text { adopters) } \\
\text { Theory used to } \\
\text { guide and frame } \\
\text { experience of } \\
\text { implementation } \\
\text { over time. Senior } \\
\text { leadership use } \\
\text { diffusion of } \\
\text { innovation } \\
\text { terminology to } \\
\text { explain process }\end{array}$ & $\begin{array}{l}\text { Implementation } \\
\text { process described } \\
\text { as "organic". Started } \\
\text { with staff } \\
\text { engagement. } \\
\text { Moved to re- } \\
\text { alignment of school } \\
\text { policies and clarifi- } \\
\text { cation of school } \\
\text { values. Transitioned } \\
\text { to establishing re- } \\
\text { storative practice in } \\
\text { the form of routines } \\
\text { that will sustain the } \\
\text { intervention }\end{array}$ & $\begin{array}{l}\text { Funding, training of } \\
\text { school staff and } \\
\text { students, focus on } \\
\text { engagement of } \\
\text { innovators and early } \\
\text { adopters, use of } \\
\text { form tutors to build } \\
\text { staff-student class } \\
\text { relationship, curricu- } \\
\text { lum review, policy } \\
\text { and systems } \\
\text { alignment } \\
\text { Strategy involves } \\
\text { embedding } \\
\text { organisational } \\
\text { structures that } \\
\text { sustain restorative } \\
\text { practice (e.g. staff } \\
\text { selection, } \\
\text { expectation of staff } \\
\text { training, the way in } \\
\text { which staff } \\
\text { meetings are } \\
\text { conducted, } \\
\text { classroom routines, } \\
\text { how the student } \\
\text { council is run, } \\
\text { expectation of } \\
\text { student involvement } \\
\text { in high stakes } \\
\text { decisions) }\end{array}$ & $\begin{array}{l}\text { Government } \\
\text { funding, multi- } \\
\text { agency workers, } \\
\text { governors, school } \\
\text { staff, students } \\
\text { and parents }\end{array}$ & $\begin{array}{l}\text { Intervention is } \\
\text { fully embedded } \\
\text { in the school }\end{array}$ \\
\hline
\end{tabular}


Table 4 Setting, Context and Implementation Features of Restorative Practice Intervention [23] (Continued)

\begin{tabular}{|c|c|c|c|c|c|c|}
\hline \multirow[t]{2}{*}{ Setting $^{a}$} & \multirow[t]{2}{*}{ Context $^{b}$} & \multicolumn{5}{|l|}{ Implementation } \\
\hline & & $\begin{array}{l}\text { Implementation } \\
\text { Theoryc }^{c}\end{array}$ & $\begin{array}{l}\text { Implementation } \\
\text { Process }^{\mathrm{d}}\end{array}$ & $\begin{array}{l}\text { Implementation } \\
\text { Strategy }\end{array}$ & $\begin{array}{l}\text { Implementation } \\
\text { Agents }^{f}\end{array}$ & $\begin{array}{l}\text { Implementation } \\
\text { Outcomes }^{\mathrm{g}}\end{array}$ \\
\hline & $\begin{array}{l}\text { practice and } \\
\text { adaptability }\end{array}$ & & & & & \\
\hline
\end{tabular}

levels of fixed-term and permanent exclusions. Existing practices based on merit and punishment were considered punitive and ineffectual in addressing the problem:

STAFF FG1; 2: ... we were just finding we were going round and round and round in circles and not really making progress.

\section{Political}

The policy context in Wales has been increasingly focused on supporting mental health and wellbeing of children and young people, particularly within the educational context. The Well-being of Future Generations Act (2015) in Wales has mandated organisational and culture change to enhance metal health related outcomes. Meanwhile the Donaldson educational review on curriculum reform has outlined six key priorities, such as wellbeing, alongside an acknowledgement of the synergy between wellbeing and educational outcomes (Donaldson, 2016). Although in the case study school, restorative practice had been implemented for 8 years prior to data collection in 2016, and so was in advance of these political and educational changes, these policy priorities support its continued implementation.

\section{Socio-economic}

Participants acknowledged that the case study school had a lower than national average level of free school meal eligibility and a higher level of academic achievement. Thus, whilst the school cannot necessarily be characterised as atypical, there was acknowledgment that the intervention may be more difficult to implement in a more challenging context with higher levels of disadvantage:

STAFF FG1; 6 - I think there's more focus on students' perspectives here um, which students value more. Generally the behaviour here is better than at schools that I've taught at previously, though I'd say those schools are working within a different concepts, there are inherently gonna be more issues because of the intake that they have.

\section{Socio-cultural}

Participants suggested that schools tend to have entrenched pedagogic practices that are the antitheses of restorative approaches, namely punitively orientated interactions with students. There is always the risk that staff can orientate to the default approach, which can lead to extensive variation in practice:

STAFF FG1;2 - varied yeah, it is varied across the school: you can see a restorative conversation happening in quite a negative tone in one space, but in another it can be very effective so... and that's hard for young people as well because young people say "I've just had a restorative" (said in an angry voice) and actually it's like hang on a second, that's not a restorative

Participants also suggested a potential mismatch between the social and emotional competencies required for the effective delivery of a restorative approach, and a socio-cultural context that does not always privilege vulnerability and emotional openness. To mitigate against such issues, participants identified the importance of senior leadership vision and commitment as part of the implementation plan to ensure realignment of the school ethos with the restorative practice approach and staff commitment to training and delivery. Moreover, the school adopted a rather organic diffusion process, initially securing training to a small team of pastoral staff to ensure their buy in and capacity for modelling the approach before expanding to more diverse professional roles. Eventually working groups were established to ensure continued change to the socio-cultural context, with a Behaviour Research Group reviewing how the restorative practices could be sensitively translated into the setting.

Following the initial round of focus groups to coproduce the programme theory, further work was undertaken by the TDAR to refine their understanding and to create another iteration of the logic model. The second round of focus groups with staff and students was intended to confirm these outputs Importantly they provided clarity on a number of uncertainties that remained following the first round of focus groups and elicited 
aspects of the intervention and context that had still not been identified. In particular, participants focused on the socio-ecological domains beyond the inter-personal, notably family and community level processes. For example, family-based activities emerged, particularly the delivery of parenting skills, to ensure some congruence between the school ethos and family dynamic:

STAFF FG2;13: We're working with parents on the approach we would take in school particularly where children have reflected and said 'well if I did that at home this is what would happe'n ... or this is what I see at home. And that ongoing communication and collaboration with parents is really important and it's quite a long journey for some.

Taken together, this phase provided a nuanced and contextually sensitive understanding of the local innovation. At this point it is important to consider the potential for different stakeholder groups to have different perspectives on the programme theory. In the present case example, there were no significant disagreements. However, it may arise and the processes for resolving potential conflict needs further consideration.

\section{Planning to optimise intervention delivery in local contexts}

The fifth phase progresses to planning to optimise the intervention delivery in the local context. A knowledge exchange event was hosted at the school (Fig. 2). The primary purpose of the event was to reflect on the research findings and to identify if there was a mismatch between the hypothetical programme theory that should underpin the approach, and the reality of implementing it within a real-world setting. This was important in exploring if intervention delivery could be optimised to overcome contextual issues that had led to barriers to implementation (e.g. prioritisation of academic achievement), as identified in Phase 4. This is helpful when moving forward to feasibility and outcome evaluation, as it provides some assurance that a future evaluation would not be assessing a sub-optimally delivered approach.

The event also served to address an additional two aims. First, it strengthened partnership between stakeholders. Second, it reasserted the emotional investment of the school [28]. To progress to further evaluation, where the school may be required to support the sharing and delivery of practices within other institutions, it was deemed important for the school feel committed to both the intervention and research. Reflecting with stakeholders provided a positive experience that renewed enthusiasm, with many commenting on how much the school had achieved since the initial introduction of the intervention.

\section{Planning for outcome evaluation}

The sixth phase comprises planning for future outcome evaluation if appropriate. Where outcome evaluation is warranted, the type of evaluation would be most suitably assessed against the phases of evaluation prescribed by the Medical Research Centre (MRC) guidance for developing and evaluating interventions: pilot and feasibility trial, a randomised controlled trial (RCT); natural experiment or other quasi-experimental design; or longerterm implementation evaluation [3, 29]. Further work is required to refine decision-making about the most suitable evaluation approach, and an a priori progression criteria similar to that used in feasibility trials may be helpful to guide next steps after the pragmatic formative process evaluation. Potential criteria to be considered are: 1) The evaluability of the intervention [30]; 2) The Value of Information (VOI), which weighs the cost of obtaining evidence against the need for certainty amongst stakeholders [31]; and 3) the applicability of the existing evidence base to the local context. For example, Aarons et al. have developed a framework for 'borrowing evidence', which assesses the similarities of different interventions and contexts to see if the outcomes of evaluations conducted elsewhere have relevance to the new context in question [32].

In the present case study, planning is primarily being conducted through the TDAR group. The SHRN infrastructure offers a particular opportunity to continue with pragmatically orientated innovation evaluation, through the conduct of a pragmatic feasibility and outcome trial. As of 2020 the network includes $100 \%$ of the 210 statefunded schools in Wales, providing a complete sample frame for randomisation. A sample of students at each participating school complete bi-annual surveys of their health and wellbeing, and provided data is collected at appropriate times, these surveys could be exploited as the data source for outcome measurement. As popular innovations, such as that selected for the case study, are gaining traction within systems, it is imperative that we have responsive study designs. Use of routine data, such as that collected through the SHRN survey data offers such responsivity, although the evidence generated is arguably less scientifically robust than that provided by RCTs.

\section{Discussion}

In recent years there has been a proliferation of guidance on the development of complex population health interventions $[1,2]$. Such frameworks have primarily focused on the modelling of de-novo interventions. To date there has been more limited consideration of the retrospective 


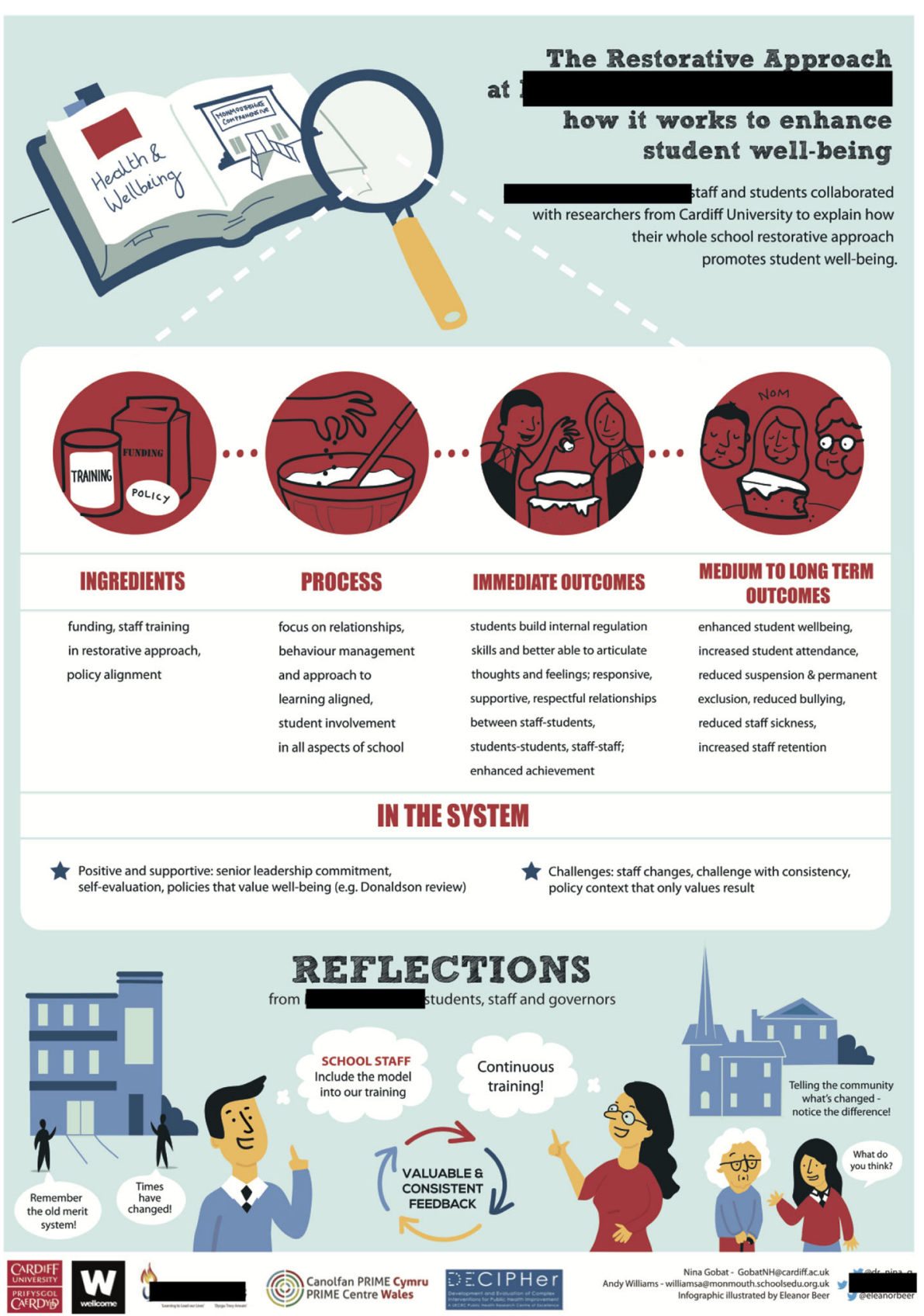

Fig. 2 Visual minutes from the whole school restorative approach stakeholder workshop

development of local innovations that are already routinised. Such approaches offer a fruitful opportunity in population health improvement. In recent years there has been growing interest in the idea that intervention effectiveness is contextually contingent. In response, a range of theoretical and methodological tools are being developed to help anticipate how context may impact upon an intervention's functioning [23, 33, 34]. Yet in the event of routinised practice, many of these contextual contingencies are already emergent or even established. This may make it easier to implement them in comparison to novel approaches, as potential barriers and facilitators may be understood.

The case study intervention, a school-based restorative practice approach addressing student mental health and wellbeing, demonstrates the utility of pragmatic formative process evaluations. To date there have been a range of restorative interventions, including that reported in the recent INCLUSIVE trial [12, 17]. While many of these studies have started to map key system influences 
that may moderate the intervention's programme theory, the case study is particularly insightful as it presents established contextual characteristics eight years into intervention implementation. These include key sociocultural factors, such as the entrenched educational ethos and pedagogic approaches [35]. Such findings also illustrate the importance of attending to intervention maintenance, and the ongoing resource required to ensure continued contextual fit. Use of context mapping frameworks, such as the CICI framework, across studies reporting on different phases of diffusion will enable researchers to understand the evolution of contextual factors and how interventions may respond to and accommodate them [23].

The six phases of intervention modelling are particularly focused on the elicitation of contextual characteristics. To this end, meaningful co-production must serve as a central feature. As with other developmental frameworks, establishment of TDAR group is recommended to ensure that a diverse range of stakeholders invested in the intervention are adequately represented $[2,25]$. The presence of this group can help ensure that phases of evaluation privilege co-production, that policy and practice stakeholders are able to make a meaningful contribution and that the modelled intervention captures a multiplicity of experiences and perspectives.

Pragmatic formative process evaluation also responds to the ever-present issue of the mismatch between the needs of policy-makers and practitioners and the reality of conducting scientifically robust evaluations. One of the key tensions is the timeliness of generating research evidence, and a perceived lack of responsiveness in the research community. Efforts to resolve these arguably incompatible needs have increasingly focused on quasiexperimental designs, with natural experiments being used to evaluate policy innovation [36]. While such designs may not provide the same level of scientific robustness as randomised controlled trials, they do allow for the generation of pragmatic and relevant evidence. The present framework for pragmatic formative process evaluation supports this direction of travel by engaging the wealth of local innovation that has already gained traction within real world settings, rather than prioritising new approaches largely developed by researchers.

\section{Limitations}

There are a number of limitations that should be acknowledged. First, as with existing developmental models focused on co-production, it is uncertain how much stakeholders should contribute to gain a nuanced understanding of the intervention [2]. The proposed phased approach risks privileging researchers' perspectives by commencing with the review and synthesis of existing literature. Equally the phases of stakeholder engagement may be inadequate in practice, and they may need to be continually repeated until the logic model is fully refined and there is consensus. Second, the representativeness of the case study school should be considered, as it had a lower than average level of free school meal eligibility, a higher than average level of academic attainment and a large student population. The field of implementation has been increasingly concerned with the generalizability of evidence when interventions are scaled-up or scaled-out [32], and there are considerations about whether the intervention could be embedded within schools of different socio-economic profiles. For example, study participants felt it would be challenging to deliver the intervention in more socioeconomically deprived settings, while extant research suggests that the quality of staff-students relationships is actually more of a priority in schools of a lower socioeconomic status [37]. Third, while maximum variation in sampling within the case study was pursued, the sample is limited by those who were prepared to participate. Focus groups were largely conducted with students engaged in classroom level activities, and did not include many individuals who had received one-to-one support. Equally, data were not available on additional student level characteristics that may have influenced perceptions of the intervention (e.g. school connectedness) and these were not addressed during recruitment. Fourth, the composition of the student focus groups, which were heterogenous in gender and school years, may have inhibited the sharing of contrasting views and encouraged students to conform to predominant norms.

\section{Conclusion}

The present study provides an empirically worked example of a pragmatic formative process evaluation to support researchers, policymakers and practitioners in the modelling, delivery and outcome evaluation of interventions already in routine practice. This phased framework serves as a complement to the emerging range of guidance for the development of de-novo population health interventions $[1,2]$, by addressing the specific developmental phases required for working with locally embedded innovation. It also responds to increased policy and practice needs, where evaluation needs to be responsive to the rapid emergence of new innovation. Further methodological and empirical work is needed to apply and refine the framework with different health outcomes, populations and settings.

\section{Abbreviations}

$\mathrm{ClCl}$ : Context and Implementation of Complex Intervention framework; DECl PHer: Centre for Development, Evaluation, Complexity and Implementation in Public Health Improvement; FSM: Free School Meal; GCSE: General

Certificate of Secondary Education; INCLUSIVE: intervention - Initiating change locally in bullying and aggression through the school environment intervention; MRC: Medical Research Centre; RCT: randomised controlled Trial; 
RSQM: Restorative Service Quality Mark; SHRN: School Health Research Network; TDAR: Transdisciplinary Action Research; VOI: Value of Information

\section{Acknowledgements}

Thanks to Elen de Lacy, Luke Midgely, and Ruth Turley for their assistance with data collection. The work was undertaken with the support of the Centre for the Development and Evaluation of Complex Interventions for Public Health Improvement (DECIPHer), a UK Clinical Research Collaboration Public Health Research: Centre of Excellence. Funding from the British Heart Foundation, Cancer Research UK, the Economic and Social Research Council (RES-590-28-0005), the Medical Research Council, the Welsh Government and the Wellcome Trust (WT087640MA), under the auspices of the UK Clinical Research Collaboration, is gratefully acknowledged.

\section{Authors' contributions}

$N G, A W, K M c E, M R, S R, S M, R E$ obtained funding and developed the study protocol. NG obtained ethical approvals. AW facilitated access to the case study school, recruited study participants, and facilitated access for the research to be conducted in the school. NG, KMcE, HS collected data. NG, $\mathrm{HL}, \mathrm{KMcE}, \mathrm{HS}, \mathrm{RE}$ analysed data. NG, HL, AW, KMcE, MR, SR, SM, RE interpreted data. NG and RE drafted the manuscript. All authors contributed and approved the final manuscript.

\section{Funding}

Wellcome Trust Institutional Strategic Support Fund at Cardiff University. The funders had no role in the no role in the design, conduct, interpretation or reporting of the study.

\section{Availability of data and materials}

The datasets generated and/or analysed during the current study are not publicly available due to protection of participant privacy and confidentiality but are available from the corresponding author on reasonable request.

\section{Ethics approval and consent to participate}

Ethical approval was obtained from Cardiff University School of Medicine Research Ethics Committee. Written informed consent was obtained from all participants. For young people under the age of 16 years, written or verbal consent was sought from parents or guardians prior to the young person's participation in the group. The ethics committee provided approval for this approach.

\section{Consent for publication}

Not applicable.

\section{Competing interests}

None declared.

\section{Author details}

${ }^{1}$ Nuffield Department of Primary Care Health Sciences, University of Oxford, Radcliffe Observatory Quarter, Woodstock Road, Oxford OX2 6GG, UK. ${ }^{2}$ School of Social Sciences, Cardiff University, Cardiff, UK. ${ }^{3}$ Independent Consultant, UK. ${ }^{4}$ Health and Social Care, University of Derby, Derby, UK.

${ }^{5}$ School of Medicine, Cardiff University, Cardiff, UK.

Received: 5 November 2019 Accepted: 23 December 2020 Published online: 18 January 2021

\section{References}

1. Wight D, Wimbush E, Jepson R, Doi L. Six steps in quality intervention development (6SQuID). J Epidemiol Community Health. 2016;70(5):520-5.

2. Hawkins J, Madden K, Fletcher A, Midgley L, Grant A, Cox G, et al. Development of a framework for the co-production and prototyping of public health interventions. BMC Public Health. 2017;17(1):689.

3. Fletcher A, Jamal F, Moore G, Evans RE, Murphy S, Bonell C. Realist complex intervention science: Applying realist principles across all phases of the Medical Research Council framework for developing and evaluating complex interventions. Evaluation (London, England : 1995). 2016;22(3):286303

4. Pawson R. The science of evaluation: a realist manifesto. London: SAGE Publications: 2013

5. Pawson R, Tilley N. Realistic evaluation. London: SAGE Publisher; 1997.
6. Hawe P, Shiell A, Riley T. Complex interventions: how "out of control" can a randomised controlled trial be? Bmj. 2004;328(7455):1561-3.

7. Hawe P, Shiell A, Riley T. Theorising interventions as events in systems. Am J Community Psychol. 2009;43(3-4):267-76.

8. Evans R, Scourfield J, Murphy S. Pragmatic, formative process evaluations of complex interventions and why we need more of them. J Epidemiol Community Health. 2015;69(10):925-6.

9. Stokols D, Hall K, \&, Vogel A. Defining transdisciplinary research and education. In: Haire-Joshu D, McBride T, editors. Transdiscplinary Public Health: Research, Methods and Practice San Francisco: Jossey-Bass Publishers.; 2013. p. pp.3-30.

10. Hopkins B Restorative approaches to bullying behaviour - breaking the cycle of power and control. Scottish Anti-Bullying Network Newsletter. 2006; Spring.

11. Morrison B, Blood $\mathrm{P}$, Thorsborne M. Practicing restorative justice in school communities: the challenge of culture change. Public Organisation Review: a global journal. 2005;5:335-57.

12. Bonell C, Fletcher A, Fitzgerald-Yau N, Hale D, Allen E, Elbourne D, et al. Initiating change locally in bullying and aggression through the school environment (INCLUSIVE): a pilot randomised controlled trial. 2015:1-109, vii-viii, 2015.

13. Welsh Government. My Local School 2018 [Available from: http:// mylocalschool.wales.gov.uk/?lang=en.

14. DECIPHer. School Health Research Network 2018 [Available from: http:// www.shrn.org.uk/.

15. Braun V, Clarke V, Terry G. Thematic analysis. Qual Res Clin Health Psychol. 2014:24:95-114.

16. QSR International PL NVivo qualitative data analysis software, version 10. 2008.

17. Bonell C, Allen E, Warren E, McGowan J, Bevilacqua L, Jamal F, et al. Effects of the learning together intervention on bullying and aggression in English secondary schools (INCLUSIVE): a cluster randomised controlled trial. Lancet. 2018;392(10163):2452-64.

18. McCluskey G, Lloyd G, Stead J, Kane J, Riddell S, Weedon E. 'I was dead restorative today': From restorative justice to restorative approaches in school. [References]: Cambridge Journal of Education. Vol.38(2), 2008, pp. 199-216.; 2008.

19. Shaw G Restorative Practices in Australian Schools: Changing Relationships, Changing Culture. Conflict Resolution Quarterly. 2007;25(1).

20. Bitel M National Evaluation of the REstorative justice in schools Programme Youth Justice Board for England and Wales; 2005.

21. Skinns L, Hough M. An Evaluation of Bristol RAiS. Institute for Criminal Policy Research: Kings College London; 2009.

22. Wong DSW, Cheng CHK, Ngan RMH, Ma SK. Program effectiveness of a whole-school approach for tackling school bullying in Hong Kong. International Journal of Offender Therapy and Comparative Criminology. 2011:55(6):846-62

23. Pfadenhauer LM, Gerhardus A, Mozygemba K, Lysdahl KB, Booth A, Hofmann B, et al. Making sense of complexity in context and implementation: the context and implementation of complex interventions (ClCl) framework. Implement Sci. 2017;12(1):21.

24. Kane J, Lloyd G, McCluskey G, Maguire R, Riddell S, Stead J, et al. Generating an inclusive ethos? Exploring the impact of restorative practices in Scottish schools. Int J Incl Educ. 2009;13(3):231-51.

25. Stokols D. Toward a science of transdisciplinary action research. Am J Community Psychol. 2006;38(1-2):63-77.

26. Heaton J, Day J, Britten N. Collaborative research and the co-production of knowledge for practice: an illustrative case study. Implementation Science. 2016;11(20)

27. Uo W-E. University of Wisconsin-Extension Program Development and evaluation. Logic Model Template. 2018.

28. Rogers EM. Diffusion of innovations: Simon and Schuster; 2010.

29. Craig P, Dieppe P, Macintyre S, Michie S, Nazareth I, Petticrew M. Developing and evaluating complex interventions: the new Medical Research Council guidance. Bmj. 2008;337.

30. Brunner R, Craig P, Watson N. Evaluability assessment: an application in a complex community improvement setting. Evaluation. 2019;25(3): 349-65.

31. Bindels J, Ramaekers B, Ramos IC, Mohseninejad L, Knies S, Grutters J, et al. Use of value of information in healthcare decision making: exploring multiple perspectives. Pharmacoeconomics. 2016;34(3):315-22. 
32. Aarons GA, Sklar M, Mustanski B, Benbow N, Brown CH. "Scaling-out" evidence-based interventions to new populations or new health care delivery systems. Implementation Science. 2017;12(1):111.

33. Moore G, Evans R, Hawkins J, Littlecott H, Melendez-Torres G, Bonell C, et al. From complex social interventions to interventions in complex social systems: future directions and unresolved questions for intervention development and evaluation. Evaluation. 2018;25(1):23-45.

34. Craig P, Di Ruggiero E, Frohlich KL, al.; e. taking account of context in population health intervention research: guidance for producers, users and funders of research. . Southampton: NIHR Journals Library; 2018.

35. Humphrey N, Lendrum A, Wigelsworth M. Making the most out of schoolbased prevention: lessons from the social and emotional aspects of learning (SEAL) programme. Emot Behav Diffic. 2013;18(3):248-60.

36. Craig P, Cooper C, Gunnell D, Haw S, Lawson K, Macintyre S, et al. Using natural experiments to evaluate population health interventions: new Medical Research Council guidance. J Epidemiol Community Health. 2012: jech-2011-200375.

37. Littlecott HJ, Moore GF, Murphy SM. Student health and well-being in secondary schools: the role of school support staff alongside teaching staff. Pastor Care Educ. 2018;36(4):297-312.

\section{Publisher's Note}

Springer Nature remains neutral with regard to jurisdictional claims in published maps and institutional affiliations.

Ready to submit your research? Choose BMC and benefit from:

- fast, convenient online submission

- thorough peer review by experienced researchers in your field

- rapid publication on acceptance

- support for research data, including large and complex data types

- gold Open Access which fosters wider collaboration and increased citations

- maximum visibility for your research: over $100 \mathrm{M}$ website views per year

At BMC, research is always in progress.

Learn more biomedcentral.com/submissions 